\title{
A SÉRIE DE LIVROS DE LEITURA PARA A AMÉRICA LATINA NO CONTEXTO DA POLÍTICA DO INSTITUTE OF INTER- AMERICAN AFFAIRS (USA) ${ }^{1}$
}

Eliane Peres ${ }^{2}$

\section{RESUMO}

Este artigo analisa uma série de livros de leitura produzida nos anos de 1940, no contexto da política norte-americana para a América Latina, conhecida como "Política da Boa Vizinhança". A produção desses livros resultou de um acordo assinado, em 1944, entre a Divisão de Educação do então denominado Inter-American Educational Foundation, Inc., (renomeado, em 1947, como Institute of Inter-American Affairs, IIAA) e o Ministério da Educação da Guatemala. O objetivo era, contudo, que essa série fosse usada nos demais países da América do Sul e da América Central. A análise dos sete livros evidencia que havia uma estreita correlação entre os

${ }^{1}$ Este trabalho só foi possível em razão de duas instâncias de pesquisa: a primeira, no contexto do pós-doutoramento, realizado na University of Illinois at Urbana-Champaing, financiado pela Capes, em 2012; a segunda, por ocasião da concessão da bolsa de pesquisa pela Comissão Fulbright, no Programa Visiting Professor, que ocorreu em 2018, na University of Texas at San Antonio. Em 2012, quanto pesquisei a coleção em análise, os livros ainda não estavam disponíveis on line. Atualmente já estão acessíveis gratuitamente e podem ser visualizados integralmente no seguinte endereço: https://vufind.carli.illinois.edu/vfuiu/Record/uiu 6968273

2 Universidade Federal de Pelotas (UFPEL), Pelotas/RS, Brasil. 
conteúdos neles apresentados e os objetivos dos programas de cooperação, revelando nitidamente uma intencionalidade civilizatória dos Estados Unidos para com os países da América Latina.

Palavras Chave: livros didáticos, livros de leitura, Estados Unidos, América Latina.

\title{
LA SERIE DE LIBROS DE LECTURA PARA AMÉRICA LATINA EN EL CONTEXTO DE LA POLÍTICA DEL INSTITUTE OF INTER-AMERICAN AFFAIRS (USA)
}

\section{RESUMEN}

Este artículo analiza una serie de libros de lectura producida en los años 1940, en el contexto de la política norteamericana para América Latina, conocida como "Política de Buena Vecindad". La producción de estos libros resultó un acuerdo firmado, en 1944, entre la División de Educación del entonces denominado Inter-American Educational Foundation, Inc. (rebautizado, en 1947, como Institute of Inter-American Affairs, IIAA) y el Ministerio de Educación de Guatemala. Sin embargo, el objetivo era que la serie fuera utilizada en los demás países de América del Sur y de América Central. El análisis de los siete libros demuestra que había una estrecha relación entre los contenidos presentados y los objetivos de los programas de cooperación, claramente revelando una intencionalidad civilizatoria de los Estados Unidos para con los países de América Latina.

Palabras clave: libros didácticos, libros de lectura, Estados Unidos, América Latina.

\section{THE SERIES OF READING BOOKS FOR LATIN AMERICA IN THE CONTEXT OF THE POLICY OF THE INSTITUTE OF INTER-AMERICAN AFFAIRS (USA)}

\begin{abstract}
This article analyzes a series of reading textbooks produced in the 1940s, in the context of the North American policy for Latin America, known as the "Good Neighbor Policy". The production of these textbooks resulted from an agreement signed in 1944 between the Education Division of the Inter-American Educational Foundation, Inc. (renamed, in 1947, as Institute of InterAmerican Affairs, IIAA) and the Ministry of Education from Guatemala. The goal was, however, that this series of reading textbooks was used in the other countries of South America and Central America. The analysis of the seven textbooks shows that there was a close correlation between the contents presented in them and the objectives of the cooperation programs, clearly revealing the civilization intentionality of the United States for the countries from Latin American.
\end{abstract}

Keywords: school textbooks, reading books, United States of America, Latin America.

\section{LA SÉRIE DE LIVRES DE LECTURE POUR L'AMÉRIQUE LATINE DANS LE CADRE DE LA}




\section{POLITIQUE DE L'INSTITUT DES AFFAIRES INTERAMÉRICAINES (USA)}

\section{RÉSUMÉ}

Cet article analyse une série des livres de lecture qui ont été produite dans les années 1940, dans un contexte de la politique des États-Unis pour l'Amérique Latine, connue sous le nom de " Politique de bon voisinage ». La production de ces livres a été le résultat d'un accord signé en 1944 entre la Division de l'éducation alors Inter-American Educational Foundation, Inc., (renommé Institute of Inter-American Affairs, IIAA en 1947) et le Ministère de l'Éducation du Guatemala. Or, la finalité était que cette série puisse être utilisée dans d'autres pays de l'Amérique du Sud et de l'Amérique Central. L'analyse des sept livres montre qu'il avait une corrélation étroite entre les contenus y présentés et les objectifs des programmes de coopération, faisant ainsi preuve d'une intentionnalité civilisatrice des Etats-Unis en relation aux pays de l'Amérique Latine.

Mots-clés: manuels, livres de lecture, États-Unis, Amérique Latine. 


\section{INTRODUÇÃO}

O objetivo principal deste artigo é analisar uma série de livros de leitura graduada produzida no âmbito dos programas norte-americanos para a América Latina no pós-guerra, na década de 40 do século $\mathrm{XX}$, no contexto da denominada "Política da Boa Vizinhança"3. Embora tenham sido resultado de um acordo assinado em 1944 entre a Divisão de Educação do Inter-American Educational Foundation, Inc. (renomeado, em 1947, para Institute of InterAmerican Affairs) e o Ministério da Educação da Guatemala, mais seis repúblicas latino-americanas estiveram envolvidas na produção dessa série de livros, em razão da participação em programas de cooperação educacionais: Bolívia, Costa Rica, Equador, Peru, Honduras e El Salvador. Sob a orientação da escritora norte-americana Ann Nolan Clark em colaboração "com um grupo de especialistas da Guatemala, mas também das repúblicas da América Central” (IIAA, 1949, p. 17), sete dos nove livros inicialmente previstos foram publicados: (1) Linda Rita; (2) Juan, El Poblano; (3) El Buey Que Quería Vivir En La Casa; (4) El Cerdito Que Fué Al Mercado; (5) Los Patos Son Diferentes; (6) La Gallina Que Quería Aydar; (7) En El Camino De La Escuela. Impressos pelo U.S. Government Printing Office, em 1948 e 1949, os livros estavam disponíveis à venda na Guatemala, no Servicio Cooperativo Interamericano de Educación Pública e na Superintendent of Documents, em Washington, D.C., a preços que variavam entre 15 e 40 centavos de dólares ${ }^{4}$, conforme dados impressos na última página dos próprios livros.

\footnotetext{
3 A chamada política da Boa Vizinhança foi "iniciada em 1928 com a eleição do republicano Herbert Hoover (1929-1933) para a presidência dos Estados Unidos e consolidada durante a administração de Franklin Delano Roosevelt (1933-1945), o seu sucessor do Partido Democrata. Esta política procurava consolidar um ideal pan-americano adequado aos interesses norte-americanos, através do estímulo à cooperação entre os países da região, o reconhecimento de sua soberania e a identificação dos problemas comuns" (MAIO \& MAGALHÃES, 2016, p. 4).

4 O livro de menor valor, o Primeiro, custava, em 1948, \$ 0,15, o que equivaleria na moeda americana atual a \$1,58; o de maior valor, o Sétimo Livro, custava \$ o,40, em 1949, o que representaria, em valores atuais, a $\$ 4,27$ Cálculo feito em: http://www.in2013dollars.com/us/inflation/1949?amount=0.40. O cálculo feito é uma aproximação do que seriam os valores atualizados, possivelmente não correspondam exatamente ao valor real se aplicado aos dias atuais.
} 
Neste artigo, esses livros são analisados na perspectiva dos estudos da história do livro didático ${ }^{5}$, entendendo que esses suportes apresentam mais do que conteúdos escolares neutros e desinteressados, mas que são artefatos que retratam intencionalidades, projetos sociais, cosmovisões, imagens de sociedade, representações de povo, comunidade, nação, nacionalidade, raça, classe, gênero etc. Observou-se, como alerta Choppin (2004, p. 558), que:

[...] a imagem da sociedade apresentada pelos livros didáticos corresponde a uma reconstrução que obedece a motivações diversas, segundo época e local, e possui como característica comum apresentar a sociedade mais do modo como aqueles que, em seu sentido amplo, conceberam o livro didático gostariam de que ela fosse, do que como ela realmente é. Os autores de livros didáticos não são simples espectadores de seu tempo: eles reivindicam um outro status, o de agente.

Assim, tem-se em consideração que a sociedade retratada nos sete livros analisados decorreu de motivações políticas, econômicas e culturais de um tempo e locais específicos, quais sejam: a do final da Segunda Guerra Mundial e a do papel que os Estados Unidos entendia que tinha no contexto das repúblicas latino-americanas nesse período. Além disso, enfatiza-se, observando as considerações do autor citado, que se trata de imagens de como o governo norte-americano enxergava as repúblicas latino-americanas e igualmente como ele gostaria que elas de fato fossem.

Não é demais afirmar que na produção e publicação desses livros haviam intencionalidades para além de elevar o nível educacional das populações, como é reiteradamente enfatizado em documentos do governo norte-americano nesse período e contexto, especialmente considerando que [...] "os livros didáticos constituíram-se e continuam a se constituir como poderosos instrumentos de unificação, até mesmo de uniformização nacional, lingüística, cultural e ideológica (CHOPPIN, 2004, p. 561-562).

\footnotetext{
5 Ver, entre outros, Choppin (2004; 2009); Luke (1988); Bittencourt (1993); Munakata (1997).
} 
Para apresentar a referida série de livros de leitura, o artigo foi dividido em três seções. Na primeira, apresentam-se discussões mais amplas acerca das agências responsáveis pelos chamados acordos de cooperação, com ênfase no Institute of Inter-American Affairs; na segunda, expõem-se algumas ações e princípios dos programas educacionais do Institute para a América Latina; finalmente, na terceira seção, são apresentados e analisados os sete livros de leitura produzidos no bojo desses programas.

\section{O INSTITUTE OF INTER-AMERICAN AFFAIRS}

Pelo menos desde o final dos anos de 1920 os esforços americanos em estabelecer e fortalecer a "Política da Boa Vizinhança" com os outros países da América são reconhecidos. É, contudo, a década de 1940, em razão da Segunda Guerra Mundial, que marcará um momento de intensificação dessa política. Como afirmou Moura (1986, p. 12), isso era parte de uma estratégia mais ampla, na qual os Estados Unidos "procurava afirmar-se como uma grande potência e centro de um novo sistema de poder no plano internacional". Para Cramer \& Prutsch (2006, p. 785):

\footnotetext{
Em meados da década de 1940, os avanços militares da Alemanha nazista provocaram profundas preocupações de segurança nos Estados Unidos. Embora as notícias sobre os eventos na Europa tenham tido um lugar central, vários acontecimentos nas Américas aumentaram a sensação de alarme nas bases governamentais, na comunidade empresarial e nos meios de comunicação de massa.
}

Isso preocupava sobremaneira os Estados Unidos. Assim, no auge da Segunda Guerra Mundial diferentes agências e agentes norte-americanos se ocuparam das relações entre os Estados Unidos e os outros países da América, na perspectiva da "Política da "Boa Vizinhança" das relações interamericanas (ANTHONY, 1973; MOURA, 1986; CRAMER \& PRUTSCH, 2006). Uma das 
importantes agências nesse cenário, que era responsável pela coordenação dos projetos comerciais e culturais entre os Estados Unidos e os países latinoamericanos, era o Office for Coordination of Commercial and Cultural Relations between the American Republics (OCCCRBAR), criada em 1940, tendo simplificado o seu nome um ano depois para Office of the Coordinator of Inter-American Affairs, posteriormente, em 1945, foi renomeado como Office of Inter-American Affairs (OIAA) 6 .

Segundo Cramer \& Prutsch (2006), é bastante difícil fornecer uma visão sistemática sobre os campos de operações do Office of Inter-American Affairs (OIAA), não só porque ele foi responsável por uma grande variedade de atividades na América Latina, como também porque foi freqüentemente reestruturado, o que levou à perda de algumas de suas atribuições à outras agências de caráter semelhante e à assunção de novas, durante o curso de sua existência. Contudo, segundo as autoras supracitadas, entre as primeiras e mais urgentes atribuições do OIAA, estavam as medidas econômicas, que visavam eliminar canais de influência reais ou percebidos do Eixo (Alemanha, Itália e Japão) na América Latina. O treinamento de pessoal especializado em áreas estratégicas, como a aviação, por exemplo, para facilitar o funcionamento do comércio das companhias aéreas locais, foi uma das ações do OIAA nos países envolvidos nos acordos de cooperação. Ainda no campo da economia, políticas relacionadas ao armazenamento de minerais, às exportações, às comunicações, ao transporte, entre outras, estiveram na mira do Office $^{7}$, que também desenvolveu ações na área das artes, da educação, da alimentação, da saúde e do saneamento básico ${ }^{8}$, além do controle dos meios de comunicação, em especial

\footnotetext{
6 Ver, para isso, entre outros, Anthony (1973); Moura (1986); Cramer \& Prutsch (2006; 2012). Vale salientar que entre os anos de 1940 e 1944, o Office esteve sob a responsabilidade do empresário Nelson Rockefeller, que foi nomeado pelo então presidente, Franklin Roosevelt. Entre os anos de 1945-1946 foi seu diretor Wallace K. Harrison (ANTONHY, 1973, p. 7).

7 "A 'cooperação econômica' envolveu uma ampla gama de atividades, incluindo a assistência, o desenvolvimento de produtos e mercados alternativos de exportação, a diversificação das economias, o redirecionamento dos requisitos de importação dos EUA em direção às fontes latino-americanas e o estímulo aos investimentos nos EUA e turismo na região interamericanas" (CRAMER \& PRUTSCH, 2006, p. 792).

8 [...] "muitos dos programas para eliminar a malária, o ancilóstomo e outras doenças estavam
} 
do noticiário no rádio e nos jornais, dos filmes e das propagandas veiculadas no período da guerra, em razão da preocupação do alcance da influência do Eixo sobre os países da América Latina9.

Em 1947, o governo dos Estados Unidos criou outra agência, o Institute of Inter-American Affairs (IIAA), para dar continuidade a programas desenvolvidos em países da América Latina, nas áreas da saúde, saneamento, agricultura e educação. A origem do Institute foi a fusão de outras corporações do governo americano, quais sejam: Office of the Coordinator of InterAmerican Affairs e o Inter-American Educational Foundation, Inc, ambos estabelecidos nos primeiros anos da Segunda Guerra Mundial.

Em relação ao Institute of Inter-American Affairs, que aqui mais interessa, pode se ler o que segue:

Foi depois do fim da guerra - em 31 de agosto de 1945 - que as funções de informação do Office of Inter-American Affairs foram transferidas para a Secretaria de Estado, por ordem executiva; e logo em seguida, o Congresso promulgou a Lei de Intercâmbio de Informações e Educação dos Estados Unidos de 1948 para tornar permanentes as atividades de informação na América Latina [...]. Foi também após o fim da guerra - em 5 de agosto de 1947 - que o Congresso criou o atual Institute of Inter-American Affairs e o encarregou de assumir as funções das duas corporações denominadas Delaware. A Seção 2 deste Ato de 1947 determina que os propósitos do Institute serão "promover o bem-estar geral e fortalecer a amizade e o entendimento entre os

concentrados em áreas produtoras de commodities estratégicos (como a Bacia Amazônica produtora de borracha ou o vale do rio Doce, no Brasil) ou perto de locais onde as bases militares norte-americanas seriam estabelecidas. Mas a documentação interna sugere que os oficiais de saúde da OIAA estavam olhando muito além de guerra e procuraram criar as bases institucionais para um compromisso de longo prazo. Muitas das iniciativas de saúde e saneamento do OIAA foram realizadas posteriormente pelo Institute of Inter-American Affairs (IIAA), sob acordos de cooperação com governos latino-americanos. [...]" (CRAMER \& PRUTSCH, 2006, 793).

9 Segundo Cramer e Prutsch (2006), grandes estúdios de Hollywood, incluindo Disney, e uma série de pequenos produtores em outras partes do país, patrocinaram a produção de uma vasta variedade de assuntos de $16 \mathrm{~mm}$ para ser usada em campanha nos países latino-americanos; além disso, o OIAA trabalhou de perto com os grandes estúdios na produção de longasmetragens comerciais e noticiários em conformidade com os requisitos das políticas de Boa Vizinhança e da defesa hemisférica. Para o caso das políticas do Office of the Coordinator of Inter-American Affairs (OCIAA) no cinema no Brasil, particularmente em relação à Divisão de Cinema e à imagem de Carmen Miranda, ver Macedo (2013). 
povos das Repúblicas Americanas através da colaboração com outros governos e agências governamentais das Repúblicas Americanas em planejar, iniciar, auxiliar, financiar, administrar e executar programas e projetos técnicos, especialmente nos campos da saúde pública, saneamento, agricultura e educação" (IIAA, 1949, p. 2) ${ }^{10}$.

Ou seja, com o fim da Segunda Guerra Mundial, o governo norteamericano considerou que era necessária a continuidade das ações anteriormente desenvolvidas, decidindo, portanto, por dar sequência a elas, mas fundindo duas corporações em uma única agência:

O objetivo amplo e básico do programa do Institute [of InterAmerican Affairs], em todos os seus três ramos - (i) agricultura, (ii) educação (iii) saúde e saneamento - é elevar o nível de vida das pessoas nas outras repúblicas americanas. As pessoas que são acometidas por doenças, subnutridas e analfabetas não conseguem resolver seus próprios problemas, pessoais ou nacionais. Somente uma população saudável, bem alimentada e alfabetizada pode contribuir para a paz e a prosperidade. O Institute considera este objetivo amplo e básico, portanto, considerando a finalidade maior do trabalho de assegurar paz e prosperidade no Hemisfério Ocidental (IIAA, 1949, p. 11).

Segundo Moura (1986), é preciso reconhecer, por um lado, que muitas das ações da política norte-americana nesse contexto possibilitaram positivamente um intercâmbio de ideias e saberes técnico-científicos; por outro lado, contudo, segundo o autor, é necessário ressaltar que a difusão cultural e os acordos econômicos se constituíam em elementos chaves "de uma construção imperialista durante a guerra e o pós-guerra” (MOURA, 1986, p. 12).

A área da saúde era uma das principais preocupações do governo norteamericano que desenvolveu projetos, por exemplo, de saneamento básico, ações de controle da tuberculose e da malária, promoveu a vacinação da população, a construção de hospitais e de centros de saúde, o treinamento de pessoal

\footnotetext{
${ }^{10}$ As traduções do inglês, do original, são de minha responsabilidade.
} 
especializado, entre outras ações ${ }^{11}$. Como se pode observar, a atenção à saúde era um dos projetos mais importantes do Institute of Inter-American Affairs:

\begin{abstract}
Para tornar os programas de saúde eficazes, é essencial obter o apoio e a compreensão da população. A educação em saúde é, portanto, uma atividade importante. Campanhas organizadas para a educação do público na causa e no controle de doenças são exercidas em todas as repúblicas cooperantes por meio de filmes, tiras de filmes, jornais, revistas, boletins, cartazes, palestras e instrução individual. Milhões de panfletos foram distribuídos em espanhol e em português. (IIAA, 1949, p. 13).
\end{abstract}

Essas preocupações, como se poderá ver adiante, estavam expressas nas lições dos livros de leitura produzidos para a América Latina e publicados em 1948 e 1949.

O programa educacional estava concentrado especialmente no ensino elementar e secundário e na formação profissional, com ênfase na formação industrial. A principal ação nessas áreas era o treinamento de professores.

Acordos de cooperação em programas de educação, entre os anos de 1942 e 1948, foram levados à efeito nos seguintes países: Bolívia, Brasil, Chile, Costa Rica, República Dominicana, Equador, El Salvador, Guatemala, Haiti, Honduras, Nicarágua, Panamá, Paraguai e Peru. No ano de 1949, já sob a tutela do Institute of Inter-American Affairs, programas educacionais foram implementados em sete países: Bolívia, Brasil, Equador, Guatemala, Panamá, Paraguai e Peru (IIAA, 1949, p. 14).

A série de livros de leitura - sete no total, embora fosse indicado a produção de nove - decorreu desses acordos de cooperação, com especial atenção à educação rural. Na sequência serão apresentados, primeiro, alguns aspectos dos programas educacionais sob o auspício do Institute of InterAmerican Affairs, que permite compreender melhor o contexto da produção didática da série de leitura; após, serão apresentados os sete livros referidos,

\footnotetext{
${ }^{11}$ Para saber mais sobre isso ver especialmente Campos (1997).
} 
articulando seus conteúdos aos contextos de sua produção.

\section{ALGUNS ASPECTOS DOS PROGRAMAS EDUCACIONAIS DO INSTITUTE OF INTER- AMERICAN AFFAIRS PARA A AMÉRICA LATINA}

O programa de educação elementar tratava especialmente da educação rural, uma preocupação evidente do Institute of Inter-American Affairs: "em quase todos os casos, todo o sistema de educação rural exigiu reorganização. Em geral, as escolas rurais latino-americanas sofreram com a negligência, particularmente em comparação com as escolas urbanas" (IIAA, 1949, p. 14).

Sobre os alunos e professores, dizia-se que na maioria das repúblicas latino-americanas:

[...] poucos alunos recebem educação além da quarta série da escola primária; em alguns países, a maioria não recebe mais de um a dois anos de escolarização. Os edifícios escolares são inadequados; os professores rurais são muito mal pagos; há uma oferta inadequada de professores; e muitos dos professores não apenas não tiveram a formação adequada, como podem ter apenas de quatro a seis anos de ensino primário (IIAA, 1949, p. 14).

No contexto dos programas educacionais, os currículos foram revisados, uma vez que foram considerados inadequados, especialmente por serem os mesmos das escolas urbanas. Um dos argumentos principais era o de que os programas escolares não tinham qualquer influência sobre o ambiente e as necessidades dos alunos das escolas rurais; além disso teriam sido planejados sem levar em conta o nível cognitivo desses alunos.

Considerando isso, um dos temas chaves das ações educacionais era a "escola centrada na comunidade". Nos novos currículos, gradualmente revisados para dar a cada conteúdo um propósito e significado relacionado ao ambiente rural de cada país, a agricultura e a saúde foram especialmente 
reforçadas, e isso se refletirá substancialmente na coleção de livros de leitura. Ainda, cursos de higiene davam instruções simples de higiene pessoal, escolar e doméstica. Os temas da qualidade dos alimentos e da dieta adequada eram discutidos e ensinados, preferencialmente de maneira prática e especialmente nos programas de almoço escolar, com os alunos participando no planejamento e na preparação das refeições. Cursos de agricultura elementar foram implementados nos projetos de hortas escolares. Como se afirmou e como se verá adiante, os livros de leitura produzidos para essas escolas refletem, fortemente, esses princípios e conteúdos.

Portanto, a ideia da escola "centrada na comunidade" previa ações práticas e um currículo planejado para refletir a vida comunitária dos alunos e, fundamentalmente, a perspectiva era a de que os chamados "benefícios da escola" deveriam ser estendidos à toda a comunidade, ou seja, a escola era o polo educativo da comunidade e professores e professoras peças chave nesse processo. A figura da professora "educadora” da família e da comunidade aparece recorrentemente nos livros de leitura produzidos para América Latina e está amplamente apresentada em uma obra que deveria ser o livro de referência das docentes: o Teachers' Handbook. For use in Cooperative Education Programs in the Latin American Republics / For use by teachers in rural Elementary School, produzido e publicado pelo Institute, em 1953.

Ainda em relação à escola, no que tange aos programas instituídos em países da América Latina, os alunos eram organizados em clubes escolares e os pais e a comunidade eram incentivados a visitar as instituições de ensino e colaborar com os trabalhos desenvolvidos nela, disseminando as aprendizagens e vivências ali experenciadas; além disso, eram estimulados a participar das associações de pais e mestres.

Ênfase especial foi colocada na formação docente: [...] "professores selecionados são enviados por seus governos para o curso normal completo. Outros professores recebem treinamento em cursos de curta duração em escolas de verão e em institutos oficinas de professores" (IIAA, 1949, p. 15). O 
desenvolvimento de livros didáticos, manuais de professores e outros materiais pedagógicos de apoio ao ensino, foram considerados indispensáveis e eles deveriam ser adequados às realidades locais.

No Teachers' Handbook (IIAA, 1953), há seções específicas sobre livros em geral e livros didáticos em específico, esses últimos considerados a "espinha dorsal da sala de aula" (p. 34). Além disso, havia orientações sobre como esses livros didáticos deveriam ser, do ponto de vista da sua materialidade e conteúdo. O conteúdo era destacado como sendo "a autoridade" e deveria ser apresentado conforme o nível de maturidade e interesse dos alunos, além disso deveria ser bem escrito, progressivo, sequencial, lógico e ter unidade de propósito. As orientações eram, também, que o conteúdo dos livros não deveria ser muito breve, de maneira que não permitisse uma abrangência adequada, nem muito extenso para não perder o foco e ser confuso. Outros fatores além do conteúdo foram destacados para que fossem observados na produção dos livros didáticos: tamanho (livros de maior dimensão para os alunos pequenos e menores para os alunos mais velhos); tipo de letra (grande, plana e preta); ilustrações (coloridas ou preta e brancas, desenho ou fotografias, e não poderia ser apenas atrativa, mas ilustrar o conteúdo apresentado); capa e acabamento (costuras) deveriam ser duráveis e resistentes. Havia orientações de que a página de rosto deveria conter o nome do autor e suas credenciais, do ilustrador, da editora, cidade e ano. Além disso, deveria ter a página do copyright para evitar fraudes e reproduções, sumário, página com tabela de ilustrações (com os devidos créditos dos ilustradores e/ou fotógrafos), prefácio, os conteúdos propriamente ditos, em capítulos, sumário do conteúdo, questões para estudo, notas de rodapé ou finais e index. Embora essas fossem as orientações para a produção de livros didáticos, na série aqui em pauta elas não foram observadas no que tange à materialidade.

No Primeiro Livro da série, intitulado Linda Rita, com 21 páginas, há uma apresentação, que embora longa, é aqui reproduzida pela importância que tem e pelas contribuições para a compreensão do fenômeno em análise: 
A los Professores

'Linda Rita' es el primero de dos libros preparatorios para la lectura en el primer grado. Inicia una serie de libros del programa de lectura confeccionado en la América Latina bajo los auspícios de los Programas Coopertivos de Educación que desarrollan los Ministerios de Educación en Bolivia, Costa Rica, Ecuador, Guatemala, Honduras, Perú y El Salvador, conjuntamente con la División de Educacion del Institut of Inter-American Affairs (Instituto de Asuntos Interamericanos).

En estos libros se va aumentando gradualmente la complejidad del medio ambiente, de las experiencias y del vocabulario, la base de normas de aprendizage ya estabelecidas. Se introducen palavras nuevas y se presentan y desarrollan ideas o conceptos de acuerdo con la habilidade del niño para aprender.

Los libros para el primer y el segundo grados tratan del hogar, la familia, animales domésticos, joguetes y compañeros de juego. Presentan el mundo del niño a través de sus proprios, em su linguaje infantil y su pensamento de niño. Los libros para el tercer y cuarto grados se han escrito para niños cuya curiosidad y apreciación han sido ya despertadas hacian las gentes, las cosas y los hechos que se encuentran más allá de los confines del hogar. Estos libros facilitan el desarrollo más rápido de los conceptos y el vocabulario.

La serie completa del mencionado programa de lectura consta de nueve libros, siete de los cuales han sido terminados. También se han preparado um 'Manual para el Maestro', que es essencial para el programa. La primeira edición del manual há sido impresa por el Gobierno de Guatemala. Pueden adquirir se ejemplares de él por intermédio del Servicio Cooperativo Interamericano de Educación Pública, Ciudad de Guatemala, República de Guatemala.

Se han impresso cinco mil ejemplares de cada libro para usos experimentales en la América Latina. Puede solicitarse el permiso para reimprimir o adaptar estos libros al Institut of Inter-American Affairs, Washington 25, D.C. (LINDA RITA, 1948, s/p) ${ }^{12}$.

Um aspecto a ser destacado é o pioneirismo da Guatemala na assinatura do acordo para a produção e a publicação desses livros de leitura. O relatório das atividades desenvolvidas no país indica mais dados sobre a produção dessa série:

12 Todos os outros seis livros reproduzem essa apresentação nos mesmos termos, excetuando a primeira sentença que é específica para cada livro. 
Um grupo de especialistas norte-americanos, liderados pela competente escritora Ann Clark, colaborou com um grupo de especialistas da Guatemala, mas também das repúblicas da América Central, no planejamento e preparação de uma série de leitura graduada e outros materiais, especialmente escritos para se adequar ao cenário da América Central, de modo a torná-los facilmente adaptáveis a outras repúblicas que não a Guatemala, ou mesmo a ser usado nessas repúblicas sem mudanças. Livros de exercícios e outros materiais suplementares estão sendo desenvolvidos junto com os textos de leitura e espera-se que a nova série esteja em uso na abertura do ano letivo em janeiro de $1949^{13}$ (IIAA, 1949, APPENDIX, p. 17).

A escritora norte-americana Ann Clark, acima mencionada, trabalhou para o Institute of Inter-American Affairs entre os anos de 1945 e 1950. Nesse período, ela esteve no México, na Guatemala, na Costa Rica, no Equador, no Peru e no Brasil e, além de ter liderado, como mostra o excerto anteriormente reproduzido, o grupo de especialistas norte-americanos e das repúblicas da América Central no planejamento e preparação da série de leitura graduada, participou de treinamento de professores desses países e colaborou na produção de outros materiais pedagógicos. Em seu retorno aos Estados Unidos, e considerando a experiência de cinco anos no contexto da América Latina, escreveu livros infantis cujos enredos remetiam às experiências vividas.

A produção da série de leitura graduada resultou especificamente de um acordo assinado em 12 de agosto de 1944, entre a Divisão de Educação do InterAmerican Educational Foundation, Inc. (depois Institute of Inter-American Affairs) e o Ministério da Educação da Guatemala, cujo objetivo principal era planejar e executar uma ampla reorganização do sistema de educação rural do país.

Considerado um país estratégico devido suas dimensões - a maior república da América Central - e sua população - 3.500.00o habitantes, segundo dados de 1945 - a Guatemala exercia, na visão norte-americana, considerável influência em toda a região. Contudo, as condições de vida da população e a educação eram apontadas como grandes problemas na referida república.

${ }^{13}$ Nenhum outro material foi localizado. 
Segundo dados publicados pelo Institute of Inter-American Affairs (1949), havia, no país, cerca de 400.000 crianças em idade escolar, sendo que apenas 35\% estavam matriculadas na escola, de acordo com dados compilados em 1945. A taxa de analfabetismo do país era, segundo os dados, de cerca de $67 \%$ no mesmo período (IIAA,1949).

Mas os problemas mais sérios referidos eram mesmo: (i) a falta de professores e a ausência de formação adequada aos que exerciam a docência (que tinham entre quatro e seis séries do ensino fundamental e eram mal remunerados); (ii) as condições das escolas rurais, que foram consideradas insuficientes e inadequadas. Saneamento, higiene, mobiliário, iluminação, alimentação escolar, entre outros itens eram indicados como faltantes ou deficientes, especialmente nessas escolas. Além disso, o currículo e os métodos de ensino eram considerados obsoletos e inadequados para a realidade rural:

Considerando esses problemas e como o Ministério da Educação do país não tinha "funcionários especiais para o sistema escolar rural", de acordo com os planos do programa, uma nova Divisão de Educação Rural foi estabelecida no Ministério, que recebeu uma parcela significativa de seu orçamento regular.

Uma das primeiras ações do programa foi a organização de uma escola rural normal na região de Cakchiquel $^{14}$, na qual os princípios educativos propagados seriam desenvolvidos, colocados em prática, testados e demonstrados para depois serem estendidos para outras áreas através do estabelecimento de outras escolas normais rurais e através do trabalho nessas próprias escolas.

Os professores-alunos da escola normal deveriam aprender a reconhecer a importância do mobiliário adequado da escola e da boa iluminação da sala de aula, do saneamento e da limpeza escolar, entre outros aspectos

\footnotetext{
14 "A escola normal foi provisoriamente estabelecida na fábrica de uma escola agrícola abandonada na Finca La Alameda, perto da cidade de Chimaltenango. [...] o pessoal técnico dos Estados Unidos, juntamente com alguns guatemaltecos, estabeleceu residência, e a primeira turma de estudantes foi recrutada dentre os professores guatemaltecos mais promissores já em serviço" (IIAA, 1949, Appendix, p. 16).
} 
ligados às condições de saúde e de higiene. A relação entre as disciplinas escolares e a vida cotidiana do aluno e da comunidade era central no currículo dessa escola. Também foi estabelecida uma "escola prática" junto à escola normal; mais tarde, um grupo de escolas rurais regularmente estabelecidas em comunidades próximas também foram transformadas em escolas de prática e demonstração, nas quais os alunos da escola normal poderiam ganhar experiência colocando em prática as teorias aprendidas.

Assim, segundo o relatório do Institute of Inter-American Affairs (1949), apesar das dificuldades do clima e das condições longínquas e acidentadas da região, dos problemas de ausência de saneamento, de água corrente e de energia, tanto os norte-americanos quanto os guatemaltecos desenvolveram plenamente suas tarefas.

O programa estabelecido na Guatemala ainda previa as hortas escolares, que foram planejadas para cada escola rural. Com essa prática, a ideia era a de que melhores métodos de agricultura poderiam ser ensinados à população rural, novas culturas introduzidas e alguns dos suprimentos vegetais para as merendas escolares produzidos. Além disso, o ensino de economia doméstica, de artesanato, de educação física e a recreação estavam diretamente ligadas ao tema central da vida familiar rural, saúde e agricultura e era parte importante dos cursos da escola normal e do currículo das escolas rurais.

No conjunto das ações do programa foi desenvolvido também o sistema de "escola nuclear", na qual uma escola era selecionada, com base em sua localização, tamanho e importância, e então cerca de vinte escolas no bairro eram agrupadas em torno dela para formar um núcleo e receber da escola central os serviços de administração e supervisão. (IIAA, 1949, Appendix, p. 17).

Nesse cenário, outra importante tarefa dos envolvidos no programa constituiu na formulação daquilo que denominaram de uma "filosofia orientadora" que deveria estar subjacente à educação rural guatemalteca, cuja concepção defendida pelo Institute era a da escola centrada na comunidade, que foi prontamente aceita pelos professores e funcionários do país, segundo o 
Institute of Inter-American Affairs (1949, p. 16).

Os livros de leitura produzidos estavam assentados fortemente nessa filosofia orientadora, como se verá adiante, que supunha um currículo 'funcional', no qual as escolas teriam uma relação direta com a vida das comunidades rurais. Além disso, na escola normal implantada e nas escolas rurais, as temáticas da higiene pessoal, escolar, domiciliar e comunitária, os melhores métodos de agricultura, os fundamentos de nutrição, entre outros aspectos, eram parte central do currículo e estão amplamente contemplados nos livros didáticos produzidos para serem usados nos países da América Latina, como se verá a seguir.

\section{A COLEÇÃO DIDÁTICA DE LIVROS DE LEITURA PARA A AMÉRICA LATINA}

A ambiência dos sete livros de leitura é a zona rural. A população representada com características físicas dos povos da América Central e com roupas consideradas típicas e sempre descalços -, os afazeres, os animais, os produtos, as casas - de madeira e cobertas de palha -, o mercado de compra e venda da produção da comunidade e a própria vida comunitária estão no centro dos enredos das histórias. Os animais - que falam e dialogam reiteradamente nos textos apresentados - são parte importante desses enredos.

No Primeiro Livro, aparecem apenas uma menina, Rita, e sua mãe; no segundo, as personagens principais são Juan, o campesino, e sua família, não nomeados; nos livros seguintes (do Terceiro ao Sétimo) aparece uma família, da qual fazem parte, além das crianças nomeadas (Rita e Juan), Carlos Pedro e Ana Maria, o pai, a mãe, o irmão mais velho, a irmã, o bebê - todos sem nomes; além disso, todos os animais domésticos da casa são personagens importantes nos livros. A professora, D. Lolita, tem uma função fundamental no contexto das histórias, uma vez que "Ella es uma maestra" e ela sempre "[...] Sabrá qué hacer”, como aparece em uma lição do Quarto Livro, O Cerdito Que Fué Al 
Mercado (1949, p. 45).

Na Figura 1 são reproduzidas as capas dos sete livros:

Figura 1 - Capas da série de leitura, 1948-1949.

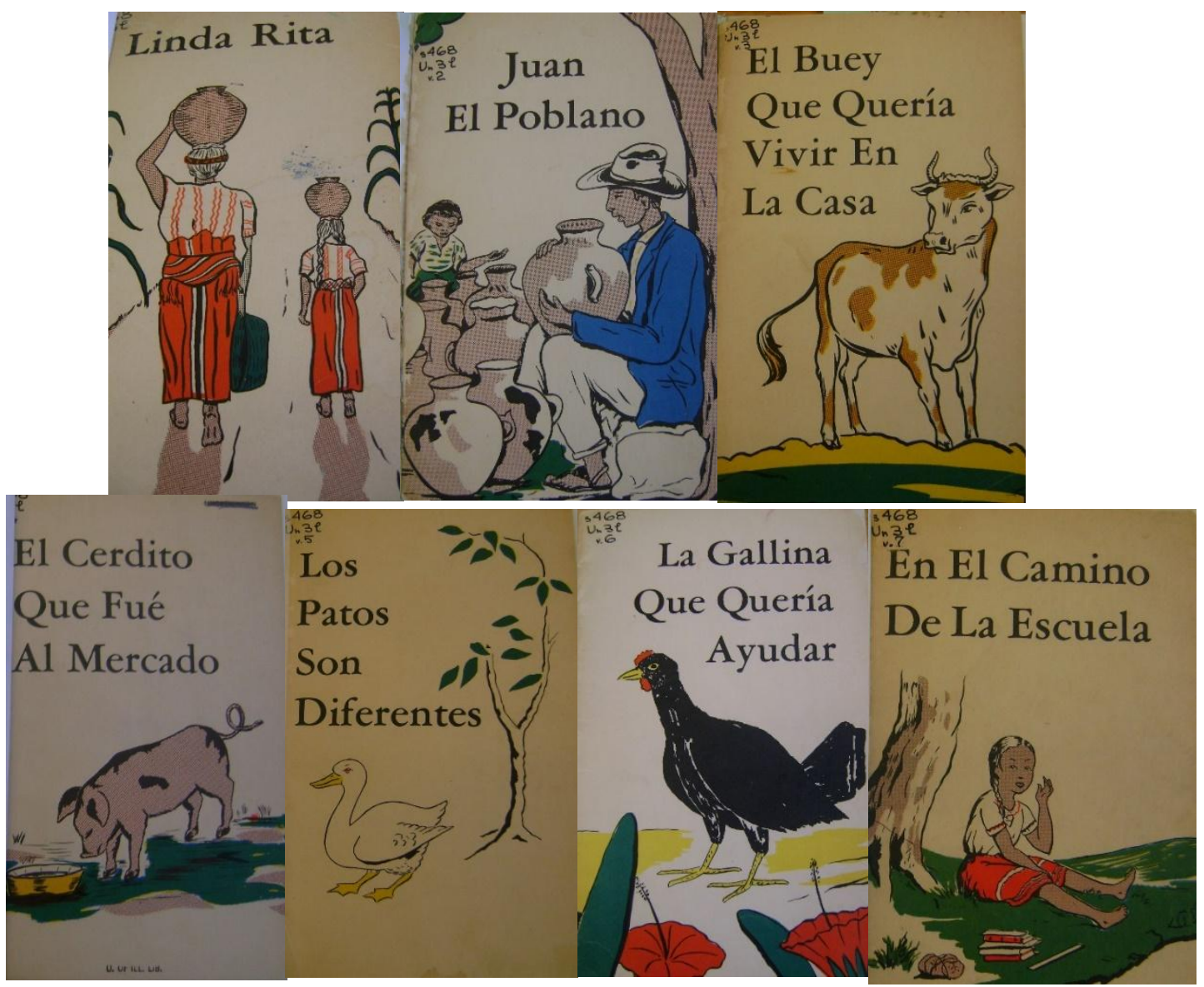

Fonte: University of Illinois at Urbana-Champaign, Fotos da autora, 2012.

Como afirmou-se, no Primeiro Livro ${ }^{15}$ aparecem apenas a menina Rita e sua mãe como personagens principais. Ambas mantêm um diálogo sobre o que levarão ao mercado para vender e o que poderão comprar. Além delas, as

15 O livro tem 21 páginas, sendo que na última há a listagem das palavras novas para fixação da aprendizagem dos alunos, que somam 12 no total, na perspectiva do método da wordrecognition. Trata-se do método de ensino da leitura e da escrita no qual a palavra é considerada a primeira e mais importante unidade de percepção e de aprendizagem. Para saber mais sobre isso ver Peres (2014). 
pessoas que estão vendendo seus produtos no mercado também aparecem nas páginas do livro, contudo sem serem caracterizadas ou nomeadas. Portanto, a narrativa gira em torno da menina e da sua mãe, da venda e da compra de produtos e do mercado. Embora os produtos a serem vendidos pela mãe e pela filha não sejam explicitamente referidos nos textos, as ilustrações revelam serem produtos agrícolas: verduras, flores, galinha e ovos, indicando a vida no espaço rural.

Os textos desse livro - e dos demais da série - são compostos de palavras ou sentenças simples, exclamativas e interrogativas, em forma de diálogo, também em razão da perspectiva de leitura que ancorava os programas educacionais do Institute of Inter-American Affairs (IIAA, 1949; 1953): a leitura deveria ser fonte de prazer, mas fundamentalmente de informação. Nos livros, há repetição de palavras nas frases, especialmente adjetivos e substantivos, e de frases nos textos, fundamentalmente as exclamativas (por vezes repetidas até três vezes) e as interrogativas. Trata-se da estrutura de texto que compunha os princípios do chamado método da word-recognition. Contudo, interessa aqui não o método de ensino, mas o conteúdo dos livros em análise, uma vez que há relação direta com os aspectos anteriormente apresentados, relacionados aos objetivos mais amplos dos programas do Institute of the Inter-American Affairs.

A completa e intensa dedicação e trabalho da professora na comunidade era o aspecto mais enfatizado nas orientações aos docentes, perspectiva presente nos textos dos livros da série. Era indicado no Teachers' Handbook (IIAA, 1953) que os professores e as professoras, ao assumir uma escola, fizessem um exaustivo survey para determinar o padrão da comunidade que deveria abranger os aspectos geográficos (localização da comunidade, tamanho, recursos naturais etc), humanos (população, taxa de nascimento e morte, divisões familiares, ocupações, residências etc), comunitários (tipos de casas, ruas e estradas, lojas, indústrias, sistema de transporte e comunicação, serviços públicos etc.). Tratava-se de minucioso escrutínio da vida familiar e 
comunitária. Depois do survey é que a professora deveria indicar as necessidades da comunidade: saneamento básico, alimentação, água potável, implantação de hortas domésticas, clubes e espaços de recreação para a comunidade etc. E somente depois disso o programa da escola estaria pronto.

Ainda segundo o Teachers' Handbook (IIAA, 1953), havia somente uma razão para que as crianças aprendessem as lições escolares: aprender para a vida, para saber manejar as situações do cotidiano. Nesse sentido era enfatizado que as "lições são aprendidas em sala de aula para serem colocadas em prática fora dela" (1953, p. 45). Pelas orientações, o caráter pragmático do ensino era fundamental, uma vez que algo que não pudesse ser usado na vida prática seria esforço desperdiçado.

Assim, no Segundo Livro, Juan, El Poblano ${ }^{16}$, o menino camponês Juan, ou Juanito como também é chamado, e sua família - o pai, a mãe, o irmão e a irmã - são artesãos produtores de potes de barro (tinajas) e a narrativa gira em torno da ida do menino ao mercado para vender os produtos. Juan, caracterizando como grande, forte e valente, carrega sozinho, no longo e difícil caminho ao mercado, sob um sol escaldante, muitos potes feitos pela família para vender. Vive muitas aventuras nessa jornada até chegar ao mercado e se instalar para vender os produtos da família, que também está no local com tal finalidade. É preciso salientar que valorizar a chamada cultura manual local e comércio da/na comunidade eram um dos princípios defendidos pelo Institute of Inter-American Affairs.

Além disso, o princípio era de que The class move into the home, ou seja, a aula move-se para dentro da casa, entra na cozinha para ensinar boa e correta alimentação, entra no pátio para ensinar a plantar vegetais, cultivar horta, criar animais para consumo alimentar, entra no mercado público para ensinar o quê e como vender e comprar, especialmente no que se relaciona aos alimentos e à boa alimentação. Os cuidados com a saúde eram, portanto, parte importante do currículo escolar proposto, além de Aritmética, Leitura e Escrita.

\footnotetext{
16 Contém 25 páginas e no final são apresentadas as palavras novas, que somam 37 nesse caso.
} 
Os programas de ensino, por exemplo, previam que as crianças deveriam ser ensinadas, na classe, a manter o corpo e as roupas limpas, a lavar as mãos, pés e dentes em água corrente, a alimentar-se adequadamente, a beber água filtrada ou fervida, a manter boa saúde mental e física (IIAA, 1953) ${ }^{17}$.

Assim sendo, ensinar só teria sentido se os ensinamentos da sala de aula alcançassem os pais e toda a família. Saúde, saneamento e nutrição eram as palavras chaves do ensino. Se o professor não atingisse a família através das crianças, se igualmente não ensinasse os alunos e aos seus pais, estava fracassando em sua missão. Portanto, conhecer a situação da saúde de cada criança e de cada casa da comunidade era considerado prioridade, tanto a saúde física quanto a mental. Ensinar a lavar as mãos, o rosto, os dentes e pentear os cabelos deveria ser parte do programa escolar diário. Detectar doenças, condições inadequadas de saneamento e maus hábitos alimentares e enfatizar o cuidado pessoal e doméstico eram aspectos reiteradamente enfatizados no Teachers' Handbook (IIAA, 1953) como sendo tarefas das professoras.

Na sequência da série de livros de leitura vem o El Buey Que Quería Vivir En La Casa. Como se trata do Terceiro Livro ${ }^{18}$, os diálogos são mais longos e a narrativa gira em torno, como o título indica, do boi “café e branco", grande, forte, bom, que não era feliz porque queria viver na casa. As crianças, Ana Maria e Carlos Pedro, a irmã e o irmão mais velhos (ambos sem nome), o pai, a mãe, os animais que vivem na casa ou em suas "casas" - o cachorro, o gato, o pato, a galinha, o porco - tentam entender porque o boi quer viver na casa da família e porque não era feliz. Depois de tentativas frustradas de resolver o problema decidem por chamar alguém mais qualificado para encontrar a solução de tão grave problema: a Senhorita Lolita, a professora.

A solução sugerida pela professora foi a construção de uma casa para o boi e a compra de um animal mais jovem para fazer companhia ao "velho boi". A

17 O Teachers' Handbook (IIAA, 1953) apresenta o programa detalhado para todas as séries e para todas as áreas do currículo escolar.

${ }^{18}$ Ao final do Terceiro livro, com 45 páginas, são apresentadas 55 palavras novas, na perspectiva do método da word-recognition. 
seguir, na Figura 2, está parte da referida lição:

Figura 2 - El Buey Que Quería Vivir En La Casa, 1948, p. 24-25.

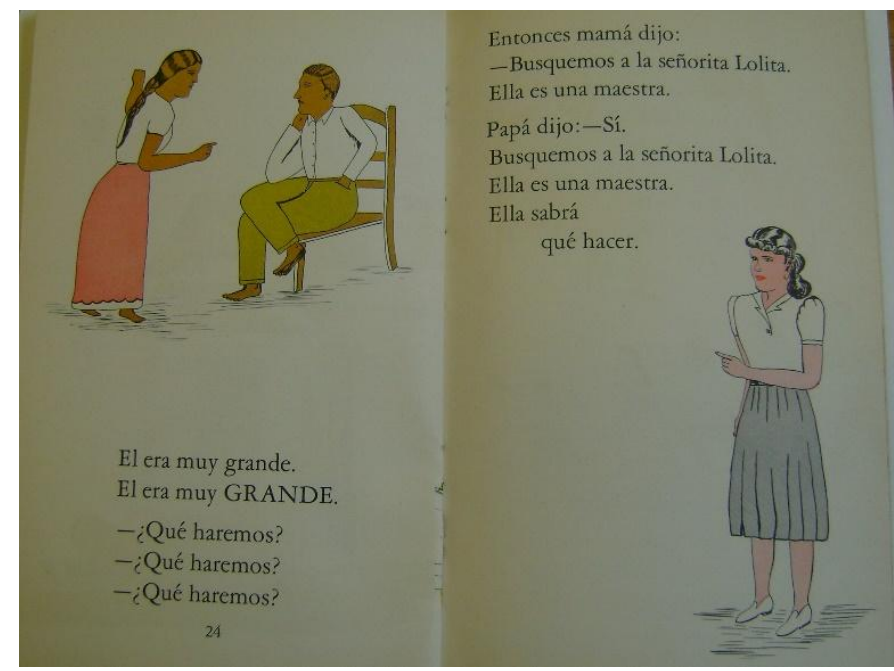

Fonte: University of Illinois at Urbana-Champaign, Foto da autora, 2012.

Não é por acaso que no livro a professora - branca, bem vestida e usando calçados - é chamada a resolver um sério problema doméstico e rapidamente encontra a solução. Segundo o Teachers' Handbook (IIAA, 1953), a maestra era a guia, a líder, a protetora, a conselheira, a orientadora, o modelo, o exemplo dentro e fora da sala de aula. Assim, as professoras deveriam ter boa saúde física e mental, práticas saudáveis de limpeza, de higiene pessoal e de alimentação, ter uma casa ordenada, limpa, pequena, iluminada, arejada, atrativa, com jardim e horta bem cuidadas, orientar a alimentação da sua própria família e das famílias da comunidade, ter cuidado com o corpo, os cabelos, os calçados e as roupas, que deveriam sempre ser limpas e adequadas. Um corpo limpo, uma mente limpa e um espírito corajoso e de liderança eram as características de uma boa professora. Além disso, precisariam saber muito mais do que aquilo que deveriam ensinar, além dos conteúdos deveriam saber e apreciar música, artes, psicologia, métodos de ensino, entre outras coisas.

Reiteradamente é enfatizado que as professoras deveriam cuidar da saúde física e mental das crianças e de suas famílias, da limpeza de seus corpos, 
dos espaços da comunidade, do conforto, do bem-estar e da alimentação dos membros da comunidade, ensinando a todos a beber água limpa, a comer frutas e legumes e a tomar banho diariamente. Era sua responsabilidade também trabalhar na profilaxia das doenças, ensinar a todos como viver em espaços higienizados, além de desenvolver bons hábitos pessoais e sociais. Deveriam, ainda, conhecer as capacidades, habilidades, necessidades, deficiências, incluindo as nutricionais, os desajustes, os hábitos individuais e coletivos das crianças e das famílias, em resumo, saber das condições físicas, mentais e espirituais de todos.

As professoras eram então as responsáveis pela aprendizagem, mas também pelo desenvolvimento e bem-estar físico e psicológico, pelo conforto, pela alegria e pelo sucesso, incluindo o financeiro, das famílias da comunidade em que atuavam. A professora que falhasse nisso, falharia como cidadã, como profissional e como ser humano (IIAA, 1953). Daí que a representação de docente como alguém com essa grandiosa missão e com essas características é apresentada na série de livros de leitura graduada.

O Quarto Livro intitula-se El Cerdito Que Fué Al Mercado ${ }^{19}$ e o enredo revela também a perspectiva da política dos programas de cooperação estadunidenses para a América Latina e das necessárias e obrigatórias ações das professoras nesse contexto. As crianças, Ana Maria e Carlos Pedro, adotam um porquinho de estimação. $\mathrm{O}$ animal vai crescendo e engordando rapidamente e os pais insistem, a todo momento, relembrando às crianças que ele deverá ser vendido no mercado para fazer dinheiro à família. Contudo, o porco - o cerdito , bem cuidado pelas crianças, come verduras e frutas e toma banho com sabão, estando sempre limpinho e cheiroso. Levado ao mercado para venda, as crianças descobrem que o abate seria seu destino, possibilidade rejeitada, obviamente, por elas. Assim, para resolver o problema decidem chamar a professora, D. Lolita, que prontamente encontra a solução: o cerdito poderia

19 O livro tem 54 páginas e, ao final, são apresentadas 71 palavras novas para fixação pelos alunos. 
garantir o dinheiro para o sustento da família de outra forma que não sua venda para o abate, a maestra levaria o cerdito com ela para que ele pudesse ajudá-la nas lições de higiene e boa alimentação na escola e na comunidade! Portanto, outra vez as lições da escola deveriam se estender ao lar, à família, aos pais e à comunidade. A higiene e a boa alimentação eram o cerne dessa formação escolar estendida à vida cotidiana. O cerdito, nesse caso, era o modelo da boa e adequada forma de vida a ser seguida por todos.

No Quinto Livro, Los Patos Son Diferentes ${ }^{20}$, novamente os temas das lições giram em torno dos princípios de higiene, da limpeza e da boa alimentação ensinadas e incentivadas pela professora, Senhorita Lolita. Nesse caso, o cerdito - o mesmo do livro anterior - era tão gordo, tão bem alimentado e extremamente limpo, que passou a viver com a professora, que visita a família com o cerdo, exemplo de limpeza e boa alimentação, para novas lições. Não por acaso, certamente, o exemplo de asseio e de uma alimentação adequada é representado na série por um porco!

Na espera dessa visita diária - que era feita de carro, sendo a professora a única personagem da série que usa esse meio de transporte em detrimento dos animais e carroças usadas pelas famílias -, os outros animais da casa se esmeram no asseio de si, da casa e dos seus arredores. A professora elogia reiteradamente a casa limpa, os animais asseados, o cuidado com o local, além da alimentação saudável, uma vez que ela compartilha as refeições nessas visitas. Nesse livro, diante dos elogios da professora acerca da boa alimentação e da higiene, a mãe pergunta o que pode ela então ensinar de novo para a família. E eis que a nova lição da professora, D. Lolita, é sobre a importância de beber água limpa! E ensina à família a necessidade de ferver a água para o consumo. Nesse contexto e nessa visão edílica da vida, segundo os preceitos da "boa e correta civilização", apenas o pato não era feliz! Ele acaba por queimar as bananeiras porque também queria água fervida para tomar. A família convence o pato de que água fervida é para as pessoas, os patos são diferentes, daí o título

${ }^{20} \mathrm{O}$ livro tem 35 páginas e, nesse caso, há 60 palavras novas no final. 
do livro.

Como destacou-se, as doenças e as infecções eram uma preocupação latente no contexto dos programas estabelecidos pelos Estados Unidos para a América Latina. Doenças como a tuberculose, a malária e a disenteria eram consideradas "ladrões cruéis" da vida nacional, da felicidade, da eficiência e da grandeza nacional (IIAA, 1953, p. 18). O mal uso do solo e da água, a alimentação e a moradia pobres, a falta de calçados, entre outros, eram também considerados problemas sérios nos países alvo dos programas. A educação para a saúde era, pois, responsabilidade direta dos professores e professoras. Nesse sentido é que a inspeção de saúde pelos docentes era muito importante, crucial na vida da comunidade. A ideia defendida era a de que "crianças limpas ajudam a tornar as crianças saudáveis e a saúde é a espinha dorsal da nação” (IIAA, 1953, p. 23).

Os dados do Institute of Inter-American Affairs revelam a relação entre o trabalho desenvolvido nas repúblicas da América Central e do Sul e os currículos e conteúdos escolares expressos na série de livros de leituras aqui em pauta. O registro revela que a ênfase do trabalho foi:

(...) na provisão de sistemas de abastecimento de água, a construção de sistemas de esgoto, a construção e o equipamento de hospitais e de centros de saúde, o controle de doenças específicas, tais como malária, a febre amarela, a bouba e a disenteria, o saneamento ambiental, a educação em saúde, o registro de estatísticas importantes, o treinamento de pessoal médico e de enfermagem. [...] O programa agrícola, particularmente devido às exigências do período de guerra, concentrou-se no desenvolvimento de suprimentos adequados de alimentos, na introdução de melhores variedades de plantas e de animais, na conservação do solo e da água, no trabalho de extensão agrícola, na introdução de melhores ferramentas e métodos de cultivo agrícola, na organização de estatísticas agrícolas básicas, no trabalho de nutrição e na formação de pessoal (IIAA, 1949, p. 3). 
No Sexto Livro, La Gallina Que Quería Aydar²1, o enredo gira em torno do bebê da família - que pela primeira vez é representada com todos os integrantes juntos -, que recebe conselhos do cerdito para torná-lo o melhor de todos, ou seja, grande, gordo, forte, limpo e feliz para poder participar do concurso de bebês, no mercado da capital. Além da família, todos os animais tinham uma proposta para ajudá-lo a ser o mais belo bebê: o cachorro (podia ensiná-lo a rir), o gato (iria ensiná-lo a dormir), o pato (pretendia ensiná-lo a nadar), o cerdo (iria prepará-lo para o concurso de bebês). Contudo, a galinha não sabia como ajudar. Depois de muitas e variadas propostas da galinha de possibilidades de ajuda, rejeitadas por todos, ela, sem serventia, resolve ir para bem longe da casa. Na sequência da história, chega a maestra e todos perguntam quem pode ajudar o bebê a ser forte. Sua resposta é: uma galinha, porque, segundo D. Lolita, os bebês para serem fortes precisam comer um ovo diariamente. A galinha retorna e ajuda sobremaneira pondo um ovo diário para que o bebê pudesse alimentar-se adequadamente. $O$ resultado final é que o bebê da família vence o concurso. Na imagem final do livro aparecem quatro bebês, sendo o da família o maior, mais gordo e roliço de todos. A história remete, pois, para a importância da alimentação saudável e correta, tão perseguida pelos programas do governo norte-americano no contexto dos acordos de cooperação. Além disso, apresenta a representação de bebês sadios como sendo necessariamente gordos, roliços e fortes, associando a isso também a ideia de bebês felizes! O esforço e o empenho da família, retratado nos textos desse livro, para desenvolver essas características no bebê, dão também a dimensão de um projeto de infância para a América Latina.

Finalmente, no Sétimo Livro, En El Camino De La Escuela ${ }^{22}$, há textos e canciónes sobre a vida, o trabalho, a escola, a igreja, o mercado, entre outros. Nas mais de sessenta páginas do livro são apresentadas as atividades de cada um dos integrantes da família: a mãe que cuida da casa, do preparo do café da manhã e vai ao mercado vender os produtos, o pai que cuida dos animais da

${ }^{21}$ Tem 43 páginas e são apresentadas 36 palavras novas no final.

${ }^{22} \mathrm{O}$ livro tem 76 páginas e não há palavras novas no final. 
família, o irmão mais velho, leiteiro, que vai ao trabalho na casa do patrão e ao mercado vender o leite, a irmã que vai ao rio para lavar a roupa da família e as crianças - narradoras - que vão à escola de cara limpa, de mãos limpas, de pés limpos, de roupas limpas, com os livros e cadernos arrumados, mirando a casa que fica para trás e observando o caminho onde tudo é limpo, organizado, brilhante, florido, verde. Além disso, há textos que reforçam os hábitos alimentares da família que incluía muitas frutas e verduras.

A ideia de que trabalhar é bom e de que o trabalho das crianças é a escola, é reiterado, por exemplo, em textos como esse: “[...] Papá me dice: Trabajar es bueno. Todos trabajan. Dios quiere que sea así”. (En El Camino De La Escuela, 1949, p. 21). Assim, no conjunto dos livros de leitura as temáticas do trabalho, da higiene, da saúde, da alimentação são repetidamente tratadas, sob diferentes perspectivas e situações, reiterando um projeto social para a América Latina.

\section{CONSIDERAÇÕES FINAIS}

Na política intervencionista norte-americana para a América Latina no pós-guerra, a produção de materiais didático-pedagógicos foi fundamental, em especial a elaboração e a publicação de livros didáticos. Como se pôde ver no caso estudado, os conteúdos dos sete livros da série de leitura produzidos sob o auspício do Institute of Inter-American Affairs, sob a liderança da escritora norte americana Ann Nolan Clark, estavam diretamente relacionados com as áreas e os princípios propugnados nos programas direcionados aos países latino-americanos: saúde, saneamento, agricultura e educação.

Na edição desses livros, a Guatemala teve um papel essencial. O país foi considerado peça chave nesses programas, pela sua posição geográfica, índice populacional e por ser o maior país da América Central. No que tange à editoração da série de livros sob a tutela dos programas educacionais dos 
Estados Unidos, o país foi, assim, pioneiro no período e no contexto analisados.

A escola, a formação docente, os materiais didático pedagógicos foram estratégias importantes para que os Estados Unidos alcançassem o objetivo da "Política da Boa Vizinhança”. A figura da professora, nessa política, ganhou centralidade. Os textos dos sete livros de leitura analisados indicam claramente para isso. D. Lolita, a maestra, tem funções importantes e é chamada sempre que há necessidade da solução de algum problema da família e/ou da comunidade. Além disso, há recorrência de textos em que são destacados a importância da alimentação saudável, especialmente com o consumo de frutas e verduras frescas, do trabalho, das relações de compra e venda no mercado local, da escola, da limpeza e do asseio, do cultivo de produtos, da profilaxia das doenças, entre outros aspectos.

Os livros de leitura, de acordo com os princípios e ideias que sustentavam os programas de cooperação norte-americanos, revelam o intuito de, pela escola e pela educação, promover um processo civilizatório das e para as populações da América Latina. Essa educação para a civilização supunha ensinar às comunidades locais comer, beber, morar, plantar, trabalhar, produzir e vestir-se de acordo com aquilo que era considerado adequado, prevenir doenças, tratar e cuidar da saúde, comercializar os produtos, vender e comprar, organizar a vida cotidiana etc. É preciso relembrar que o declarado propósito norte-americano era "elevar o nível de vida das pessoas nas outras repúblicas americanas”, uma vez que "as pessoas que são acometidas por doenças, subnutridas e analfabetas não conseguem resolver seus próprios problemas, pessoais ou nacionais. Somente uma população saudável, bem alimentada e alfabetizada pode contribuir para a paz e a prosperidade” (IIAA, 1949, p. 11). Esses propósitos - embora se saiba que eles eram bem mais amplos - estão expressos nos livros de leitura. Nesse sentido é que nunca é demais relembrar, como afirmou Choppin (2004, p. 562), que analisar livros escolares e seus conteúdos "sem levar em conta as regras que o poder político, ou religioso, impõe aos diversos agentes do sistema educativo, quer seja no domínio político, 
econômico, lingüístico, editorial, pedagógico ou financeiro, não faz qualquer sentido".

\section{REFERÊNCIAS}

ANTHONY, Edwin D. Records of the Office of Inter-American Affairs. National Archives and Records Service. General Service Administration. Washington, 1973.

BITTENCOURT, Circe Maria Fernandes. Livro didático e conhecimento histórico: uma história do saber escolar. Tese (Doutorado)- FFLCH, Universidade de São Paulo, São Paulo, 1993.

CAMPOS, André Luiz Vieira de. International Health Policies in Brazil: The Serviço Especial de Saúde Pública, 1942 - 1960. (Ph.D. Diss., University of Texas at Austin), 1997.

CHOPPIN, Alain. História dos livros e das edições didáticas: sobre o estado da arte. Educação e Pesquisa, São Paulo, v. 30, n. 3, p. 549-566, set./dez. 2004. CHOPPIN, Alain. O manual escolar: uma falsa evidência histórica. História da Educação. Pelotas: ASPHE, v. 13, n. 27, p. 9-75, jan./abr., 2009.

CRAMER, Gisela; PRUTSCH, Ursula. Nelson A. Rockefeller's Office of InterAmerican Affairs and the Quest for Pan-American Unity: An Introductory Essay. Hispanic American Historical Review 86:4 Duke University Press, 2006. (p.785-805).

CRAMER, Gisela; PRUTSCH, Ursula. iAméricas unidas! : Nelson A.

Rockefeller's Office of Inter-American Affairs (1940-46). Madrid:

Iberoamericana Vervuert, 2012.

INSTITUTE OF INTER-AMERICAN AFFAIRS (U.S.). The Program of the Institute of Inter-American Affairs. Washington, 1949. Available https://babel.hathitrust.org/cgi/pt?id=txu.059173018570342;view=1up;seq=6

INSTITUTE OF INTER-AMERICAN AFFAIRS (U.S.). Teachers, handbook for use by teachers in rural elementary schools, developed through the collaboration of Latin American and United States educators under the direction of Ann Nolan Clark. Washington, 1953. 149p. Available:

https://babel.hathitrust.org/cgi/pt?id=mdp.39015023462107;view=1up;seq=6 
INSTITUTE OF INTER-AMERICAN AFFAIRS (U.S.). Linda Rita. Libros Del Programa de Lectura Confeccionado En La America Latina: Washington, D.C, 1948.

INSTITUTE OF INTER-AMERICAN AFFAIRS. (U.S.). Juan, El Poblano. Libros Del Programa de Lectura Confeccionado En La America Latina: Washington, D.C, 1948.

INSTITUTE OF INTER-AMERICAN AFFAIRS. (U.S.). El Buey Que Quería Vivir En La Casa. Libros Del Programa de Lectura Confeccionado En La America Latina: Washington, D.C, 1948.

INSTITUTE OF INTER-AMERICAN AFFAIRS (U.S.). El Cerdito Que Fué Al Mercado. Libros Del Programa de Lectura Confeccionado En La America Latina: Washington, D.C, 1949.

INSTITUTE OF INTER-AMERICAN AFFAIRS (U.S.). Los Patos Son Diferentes. Libros Del Programa de Lectura Confeccionado En La America Latina: Washington, D.C, 1948.

INSTITUTE OF INTER-AMERICAN AFFAIRS (U.S.). La Gallina Que Quería Aydar. Libros Del Programa de Lectura Confeccionado En La America Latina: Washington, D.C, 1948.

INSTITUTE OF INTER-AMERICAN AFFAIRS (U.S.). En El Camino De La Escuela. Libros Del Programa de Lectura Confeccionado En La America Latina: Washington, D.C, 1949.

LUKE, A. Literacy, Textbooks and Ideology: Postwar Literacy Instruction and the Mythology of Dick and Jane. Philadelphia: The Falmer Press, 1988.

MUNAKATA, Kazumi. Produzindo livros didáticos e paradidáticos. 218 f. Tese (Doutorado em História e Filosofia da Educação). - Pontifícia Universidade Católica de São Paulo (PUC-SP), São Paulo, 1997.

MACEDO, Káritha Bernardo de. O "Office of the Coordinator of Inter-American Affairs" entra em cena: novas abordagens para uma Política de Boa Vizinhança. $9^{\circ}$ encontro de História da Mídia. UFOP, Ouro Preto, MG, 2013. Anais... Disponível em http://www.ufrgs.br/alcar/encontros-nacionais-1/9o-encontro2013/artigos/gt-historia-da-midia-audiovisual-e-visual/o-201coffice-of-thecoordinator-of-inter-american-affairs201d-entra-em-cena-novas-abordagenspara-uma-politica-de-boa-vizinhanca. Acesso em 22, Set., 2018.

MAIO, Marcos Chor; MAGALHAES, Rodrigo Cesar da Silva. Seja Bem-vindo Vizinho: a viagem de Heitor Praguer Fróes pelos Estados Unidos e a 
reconstrução da campanha contra a febre amarela nas Américas (1943-1947).

História, Franca, v. 35, e107, 2016. Available from

http://www.scielo.br/scielo.php?script=sci_arttext\&pid=So101-

90742016000100516\&lng=en\&nrm=iso. access on 05 May 2019.

MOURA, Gerson. Tio Sam chega ao Brasil: a penetração cultural americana. São Paulo: Brasiliense,1986.

PERES, Eliane. Influências do pensamento norte-americano na produção de cartilhas para o ensino da leitura e da escrita no Rio Grande do Sul na década de 1960. In: MORTATTI, Maria do Rosário L.; FRADE, Isabel Cristina A. da S. (Org.). História do Ensino de Leitura e Escrita. Métodos e Material Didático. 1ed. Marília: Editora da UNESP/Oficina Universitária, 2014.

ELIANE PERES é Professora Titular do Departamento de Ensino da Faculdade de Educação da Universidade Federal de Pelotas (UFPel). Possui graduação em Pedagogia pela Universidade Estadual de Londrina (1989), Especialização em Educação pela Universidade Federal de Pelotas (1992), Mestrado em Educação pela Universidade Federal do Rio Grande do Sul (1995) e Doutorado em Educação pela Universidade Federal de Minas Gerais (2000), com Estágio no Exterior (PDEE/CAPES) na Universidade de Lisboa. Realizou estágio de pós-doutorado (CAPES) na University of Illinois at Urbana-Champaign (USA) em 2011-2012. Foi Fulbright Visiting Professor na University of Texas at San Antonio (USA), em 2018. É coordenadora do centro de memória e pesquisa Hisales (História da Alfabetização, Leitura, Escrita e dos Livros Escolares) e atua na linha de pesquisa Cultura Escrita, Aprendizagem e Linguagens do PPGE (FaE/UFPel). É coordenadora do GT 10 - Alfabetização, Leitura e Escrita, da ANPED (2017-2019/ 2020-2021).

E-mail: eteperes@gmail.com

(b) http://orcid.org/0000-0002-0160-1276

Recebido em: 13 de junho de 2019

Aprovado em: 13 de novembro de 2019

Revista História da Educação - RHE

Associação Sul-Rio-Grandense de Pesquisadores em História da Educação - Asphe

Artigo de acesso aberto distribuído nos termos de licença Creative Commons. 